NASA/TP-2013-218143

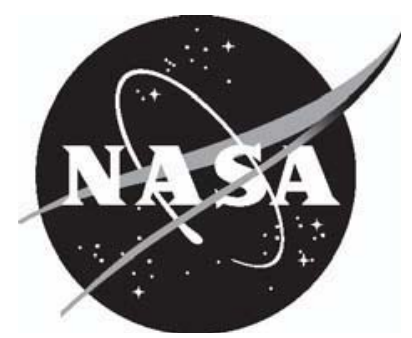

\title{
Observation of Intralaminar Cracking in the Edge Crack Torsion Specimen
}

Michael W. Czabaj

Langley Research Center, Hampton, Virginia

James G. Ratcliffe

National Institute of Aerospace, Hampton, Virginia

Barry D. Davidson

Syracuse University, Syracuse, New York 


\section{NASA STI Program . . . in Profile}

Since its founding, NASA has been dedicated to the advancement of aeronautics and space science. The NASA scientific and technical information (STI) program plays a key part in helping NASA maintain this important role.

The NASA STI program operates under the auspices of the Agency Chief Information Officer. It collects, organizes, provides for archiving, and disseminates NASA's STI. The NASA STI program provides access to the NASA Aeronautics and Space Database and its public interface, the NASA Technical Report Server, thus providing one of the largest collections of aeronautical and space science STI in the world. Results are published in both non-NASA channels and by NASA in the NASA STI Report Series, which includes the following report types:

- TECHNICAL PUBLICATION. Reports of completed research or a major significant phase of research that present the results of NASA Programs and include extensive data or theoretical analysis. Includes compilations of significant scientific and technical data and information deemed to be of continuing reference value. NASA counterpart of peerreviewed formal professional papers, but having less stringent limitations on manuscript length and extent of graphic presentations.

- TECHNICAL MEMORANDUM. Scientific and technical findings that are preliminary or of specialized interest, e.g., quick release reports, working papers, and bibliographies that contain minimal annotation. Does not contain extensive analysis.

- CONTRACTOR REPORT. Scientific and technical findings by NASA-sponsored contractors and grantees.
- CONFERENCE PUBLICATION. Collected papers from scientific and technical conferences, symposia, seminars, or other meetings sponsored or cosponsored by NASA.

- SPECIAL PUBLICATION. Scientific, technical, or historical information from NASA programs, projects, and missions, often concerned with subjects having substantial public interest.

- TECHNICAL TRANSLATION. English-language translations of foreign scientific and technical material pertinent to NASA's mission.

Specialized services also include organizing and publishing research results, distributing specialized research announcements and feeds, providing information desk and personal search support, and enabling data exchange services.

For more information about the NASA STI program, see the following:

- Access the NASA STI program home page

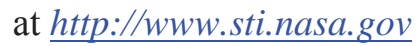

- E-mail your question to help@sti.nasa.gov

- Fax your question to the NASA STI Information Desk at 443-757-5803

- Phone the NASA STI Information Desk at 443-757-5802

- Write to:

STI Information Desk NASA Center for AeroSpace Information 7115 Standard Drive Hanover, MD 21076-1320 
NASA/TP-2013-218143

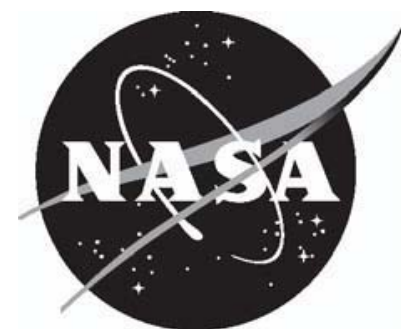

\section{Observation of Intralaminar Cracking in the Edge Crack Torsion Specimen}

Michael W. Czabaj

Langley Research Center, Hampton, Virginia

James G. Ratcliffe

National Institute of Aerospace, Hampton, Virginia

Barry D. Davidson

Syracuse University, Syracuse, New York

National Aeronautics and

Space Administration

Langley Research Center

Hampton, Virginia 23681-2199 
The use of trademarks or names of manufacturers in this report is for accurate reporting and does not constitute an official endorsement, either expressed or implied, of such products or manufacturers by the National Aeronautics and Space Administration.

Available from:

NASA Center for AeroSpace Information

7115 Standard Drive

Hanover, MD 21076-1320

443-757-5802 


\title{
OBSERVATION OF INTRALAMINAR CRACKING IN THE EDGE CRACK TORSION SPECIMEN
}

\author{
M.W. Czabaj ${ }^{1 *}$, J.G. Ratcliffe ${ }^{2}$, and B.D. Davidson ${ }^{3}$ \\ ${ }^{1}$ NASA Langley Research Center, Hampton, VA 23681 \\ ${ }^{2}$ National Institute of Aerospace, Hampton, VA 23666 \\ ${ }^{3}$ Syracuse University, Syracuse NY 13244 \\ *Corresponding author (michael.w.czabaj@nasa.gov)
}

\begin{abstract}
The edge crack torsion (ECT) test is evaluated to determine its suitability for measuring fracture toughness associated with mode III delamination growth onset. A series of ECT specimens with preimplanted inserts with different lengths is tested and examined using nondestructive and destructive techniques. Ultrasonic inspection of all tested specimens reveals that delamination growth occurs at one interface ply beneath the intended midplane interface. Sectioning and optical microscopy suggest that the observed delamination growth results from coalescence of angled intralaminar matrix cracks that form and extend across the midplane plies. The relative orientation of these cracks is approximately $45^{\circ}$ with respect to the midplane, suggesting their formation is caused by resolved principal tensile stresses arising due to the global mode-III shear loading. Examination of ECT specimens tested to loads below the level corresponding to delamination growth onset reveals that initiation of intralaminar cracking approximately coincides with the onset of nonlinearity in the specimen's force-displacement response. The existence of intralaminar cracking prior to delamination growth onset and the resulting delamination extension at an unintended interface render the ECT test, in its current form, unsuitable for characterization of mode III delamination growth onset. The broader implications of the mechanisms observed in this study are also discussed with respect to the current understanding of shear-driven delamination in tape-laminate composites.
\end{abstract}




\section{Introduction}

Delamination has long been recognized as a key failure mode for laminated fiber-reinforced polymeric (FRP) composites. In addition to growth under predominantly mode I (opening) loading conditions, delamination may also occur due to loading in mode II (in-plane shear), mode III (anti-plane shear), or some mixture of the three. Common procedures for characterizing delamination growth onset are generally based on the critical strain energy release rate, $G_{c}$, which is associated with a particular delamination mode or mode-mix. Methods for measuring $G_{c}$ associated with mode I, mode II, and mixed mode I/II delamination at unidirectional ply interfaces are well established and are available as standardized testing methods [1-3]. Although many test methods have been proposed for measuring the value of $G_{c}$ associated with mode III delamination $\left(G_{I I I c}\right)$, identifying a candidate most suitable for standardization has proven difficult. Although early efforts considered various split beam geometries [4-6], the majority of work in this area has focused on the edge crack torsion (ECT) test [7].

The ECT test geometry is depicted in Fig. 1. The specimen consists of a rectangular laminate of tape composite material that contains a preimplanted insert at its midplane, which spans the specimen length and creates an edge delamination. The specimen is twisted via equal-andopposite couples resulting in mode III dominated crack tip stresses acting along the delamination front. The two plies bounding the insert are oriented such that their fiber direction is parallel to the expected direction of delamination advance $\left(90^{\circ}\right.$ orientation in Fig. 1) [7]. This ensures that the delamination growth is in the direction of the adjacent plies consistent with the mode I, mode II and mixed-mode I/II delamination tests [1-3].

Because delamination advance cannot be visually documented during an ECT test, Lee proposed two data reduction methods for calculating $G_{I I I c}$. The first method uses a laminated plate theory solution that requires experimental determination of the compliance of the cracked regions of a test specimen. Thus, this method requires that, subsequent to fracture, test specimens are split into two halves about their midplane and the compliance of each half is measured by loading it in the ECT fixture [7,8]. The second data reduction method uses an experimental, multi-specimen compliance calibration procedure [7]. Here, multiple ECT specimens with different insert lengths, $a$, (as defined in Fig. 1) are tested. This yields a direct measurement of specimen compliance versus delamination length and avoids many of the practical difficulties associated with the former method. One disadvantage of this compliance calibration procedure, however, is that the compliance versus delamination length expression for any single specimen is based on test results from several different specimens. Regardless of the data reduction method adopted, the inability to monitor delamination propagation in an ECT specimen means that $G_{\text {IIIc }}$ corresponding only to delamination growth initiation from the insert can be measured.

A number of previous investigations into the ECT test have highlighted other issues. Ratcliffe [8] reported that the specimen's force versus deflection response deviated from linearity prior to delamination growth onset, with growth onset typically being indicated by a sudden drop in force. Also, when using the compliance calibration data reduction method, measured values of $G_{\text {IIIc }}$ were found to increase with increasing insert length. This is unexpected, given that all of these values correspond to delamination initiation from the insert, i.e., no R-curve effects should be present to cause such a dependence. X-ray inspection of ECT specimens conducted during this study suggested that the deviation from linearity was partly due to the onset of localized delamination growth and splitting of the plies bounding the insert front [8]. Analyses conducted by Ratcliffe also suggested that delamination growth onset can be stable over certain 
delamination length ranges. This implies that small amounts of delamination growth may actually occur prior to the sudden force drop.

Other researchers have reported similar observations during ECT testing. Specifically, the two most common observations are the deviation from nonlinearity in the ECT loading response and dependence of $G_{I I I c}$ on insert length. In one such study, significant nonlinearity prior to macroscopic delamination advance was observed, yet post-test X-ray radiograph examination revealed no ply splitting [9]. Through a combined experimental and numerical analysis, this nonlinearity was attributed to an R-curve effect [9]. However, R-curve behavior is intrinsically associated with delamination advance, and thus it is unclear how this mechanism affects the initiation toughness in specimens with different insert lengths. Others have reported evidence of ply splitting [10,11], fiber bridging [7,10], and migration of the delamination to other ply interfaces [7,11,12]; however, these mechanisms were not directly linked to the observed nonlinearities in the force-displacement response. In summary, there appears to be little consensus regarding the source of nonlinear behavior commonly exhibited by ECT specimens. Collectively, the uncertainties related to data reduction methods, the nonlinearities in the forcedisplacement response prior to the onset of macroscopic delamination advance, and the potential presence of additional energy dissipating mechanisms may provide an explanation for the dependency of $G_{I I I c}$ on insert length [7-10, 12-14].

Based on the above discussion, the current study re-examines the ECT test by performing a set of post-test nondestructive and destructive evaluations of the ECT specimens. Specifically, these evaluations are used to focus on the nature and evolution of damage mechanisms that occur between the onset of nonlinearity in the force-displacement response and macroscopic delamination advance. The resulting observations are used to evaluate the suitability of the ECT test for measuring mode III fracture toughness associated with delamination growth onset.

In what follows, fabrication of the ECT specimens and the test and data reduction procedures are described, including the procedure used to evaluate specimen behavior between the onset of nonlinearity and macroscopic delamination advance. Calculation of apparent $G_{I I I c}$ (labeled "apparent" $G_{I I I C}$ here due to the uncertainties of the ECT test) from the tests is presented and is followed by a description of results from ultrasonic inspections and from microscopy of sectioned ECT specimens. The paper is concluded by discussing the results and other possible implications of this study.

\section{Specimens and Fabrication}

Two $305 \mathrm{~mm} \times 305 \mathrm{~mm}$ plates from which ECT specimens were cut were manufactured as shown in Fig. 2. Here, the heavy square represents the plate's outer boundary, and the lighter, internal lines represent the cuts made to divide each plate into individual specimens, each of width $b=38.1 \mathrm{~mm}$. As indicated in the figure, each plate produced three groups of six ECT specimens with normalized insert lengths, $a / b$, ranging from 0.10 to 0.35 in increments of 0.05 . Note that after specimen machining the actual crack lengths varied slightly from the intended dimensions. This variation will be reflected in all subsequent plots. The range of insert lengths was chosen based on data from [8], where it was observed that shorter inserts encouraged more uniform delamination advance along the insert front over the length $l$ shown in Fig. 1, i.e., inbetween the loading pins. In such cases, delamination onset is expected to be more evident from the force-displacement response. The inserts, depicted as shaded regions in Fig. 2, were manufactured using a $13 \mu \mathrm{m}$ thick Teflon film. 
The ECT specimens consisted of 32 plies of IM7/8552 carbon/epoxy pre-preg. During fabrication each plate was debulked at room temperature and subsequently cured in a hot press per the recommended cure cycle from the pre-preg manufacturer [15]. The average thickness of plates 1 and 2 was $3.85 \mathrm{~mm}$ and $3.87 \mathrm{~mm}$, respectively. The stacking sequence of plate 1 specimens was modified from the original design [7] to eliminate the bend-twist couplings $\left(D_{16}\right.$ and $\left.D_{26}\right)$ in the cracked and uncracked portions of the specimen. The new, 32-ply, specially orthotropic stacking sequence was $\left[\left(90 / 45 /(-45)_{2} / 90 /(45)_{2} /-45\right)_{\mathrm{s}} \|\right]_{\mathrm{s}}$, where the "I|" symbol designates the location of the Teflon insert, and the ply orientations are as defined in Fig. 1. The stacking sequence of plate 2 was identical to plate 1 with one exception. In order to lessen the effect of fiber nesting on crack face sliding during mode III loading, the midplane plies were rotated by approximately $2^{\circ}$ in the opposite directions to each other. To balance this asymmetry, the outermost plies were also rotated by an equal and opposite amount. The resulting stacking sequence of plate 2 was $\left[-88 /\left(45 /(-45)_{2} / 90 /(45)_{2} /-45\right)_{\mathrm{S}} / 88||-88 /\left(45 /(-45)_{2} / 90 /(45)_{2} /-45\right)_{\mathrm{S}} / 88\right]$. Note that in both the cracked and uncracked regions of plate 2 , the bend-twist couplings $D_{16}$ and $D_{26}$ are zero. Due to slight asymmetry, the extension-twist couplings $B_{16}$ and $B_{26}$ are nonzero; however, these terms are quite small, and hence, their influence on the laminate's curvature is negligible. Correspondingly, no warpage of these plates was observed on cool-down or during cutting.

\section{Experimental Procedures}

\subsection{ECT test procedure}

The ECT test fixture used in this study is pictured in Fig. 3. The diameter of the loading and supporting hemispherical tipped pins is $6.4 \mathrm{~mm}$. The distance between the pins in the length and the width directions is $l=76.2 \mathrm{~mm}$ and $w=31.8 \mathrm{~mm}$, respectively. The test fixture compliance was measured and found to be less than 5 percent of the least compliant specimen. All specimens were tested quasi-statically in displacement control at a loading rate of $0.25 \mathrm{~mm} / \mathrm{min}$. The applied force and fixture displacement were recorded throughout each test once every second. The various tests conducted are described in Section 3.4.

\subsection{Data reduction}

A typical force-displacement response of an ECT specimen with $a / b \cong 0.2$ is illustrated in Fig. 4. In this figure, $P_{N L}$ designates the onset of nonlinearity in the force-displacement response determined from the procedure outlined in [8], and $P_{\max }$ is the maximum force achieved, which is typically assumed to correspond to the onset of delamination growth. The dashed line represents extrapolation of the linear portion of the force-displacement curve and is intended to illustrate the extent of the nonlinearity.

The reduction of data to obtain toughness was performed using the multi-specimen compliance calibration procedure. Here, the relationship between specimen compliance and crack length was assumed to take the form [7]:

$$
\frac{1}{C}=A[1-m(a / b)]
$$


In Eqn. (1), $C$ is specimen compliance, and $A$ and $m$ are parameters calculated by performing a linear regression analysis on the experimentally determined values of $1 / C$ versus $a / b$. In this study, the compliances of all specimens were determined over the load range 0.44 to $1.33 \mathrm{kN}$, as illustrated in Fig. 4. Apparent $G_{I I I c}$ was calculated based on the following expression [7]:

$$
G_{I I I c}=\frac{m C\left(P_{\max }\right)^{2}}{2 l b[1-m(a / b)]}
$$

\subsection{Post-test specimen inspection}

Following all tests, specimens were inspected nondestructively with an ultrasonic C-scan unit using a $10 \mathrm{MHz}$ pulse-echo transducer and $0.13 \mathrm{~mm}$ scan increment. A selected number of specimens were also sectioned and examined using an optical microscope. The specimen sectioning was performed using two distinct cuts. First, each specimen was cut along plane A-A depicted in Fig. 1. The newly exposed surface was polished in preparation for microscopy. Next, one of the two resulting specimen halves was cut lengthwise along plane B-B. The location of the plane B-B cut was slightly behind the insert front on the insert side of the specimen. After removal of the region that contained the insert, the newly created surface was ground and polished until the resin rich region that forms ahead of the insert front was fully exposed. As will be shown subsequently, this apparently new approach to assessing near-tip damage in ECT test specimens yields new and significant insights into the fracture process.

\subsection{Test matrix}

As shown in Fig. 2, specimens from each plate were divided into three groups of six specimens, where each group contained specimens with normalized insert lengths, $a / b$, from 0.10 to 0.35 . Table 1 summarizes the entire test matrix.

The first two groups of specimens from each plate were used for "apparent $G_{I I I c}$ testing." That is, these specimens were tested until there was a sudden drop in the applied force, similar to the results shown in Fig. 4, where macroscopic delamination growth was assumed to have occurred. The data from these specimens were used to compute the apparent $G_{I I I c}$ following the procedure described in Sec. 3.2. These specimens were subsequently ultrasonically inspected and sectioned as described in Sec. 3.3.

The remaining group of specimens from each plate was used for "damage progression testing." The purpose of these tests was to investigate the initiation and development of any damage that occurred between the point at which a specimen's response deviated from linearity $\left(P_{N L}\right)$ and the anticipated onset of delamination growth $\left(P_{\max }\right)$. To this end, two specimens from plate 1 were loaded until the specimens' response deviated from linearity $\left(P_{N L}\right)$, and the remaining four specimens were loaded to $95 \%$ of $P_{\max }$, where $P_{\max }$ was the average result from the group 1 and 2 specimens from plate 1 at the appropriate insert length. This approach was chosen in order to compare cross-sectional views at the two different force levels.

For plate 2 , one specimen $(a / b=0.185)$ was tested six times. In the first five loading increments, the specimen was tested to the following force levels: $P_{N L}, 82 \% P_{\max }, 87 \% P_{\max }, 91 \%$ $P_{\max }$, and $95 \% P_{\max }$. During the sixth and final force increment, the specimen was tested until macroscopic delamination growth was assumed to have occurred (as indicated by the sudden force drop). At each force level, the specimen was unloaded, removed from the test fixture, and 
ultrasonically inspected as described in Sec. 3.2. The remaining 5 specimens from the third group of plate 2 were tested to $95 \%$ of $P_{\max }$, where $P_{\max }$ is as defined above but using plate 2 specimens. Following the completion of these tests, all specimens were ultrasonically inspected, sectioned, and then optically inspected using the methods detailed in the section 3.3.

\section{Results and discussion}

\subsection{Specimen response}

The force-displacement data of specimens from group 1 of plates 1 and 2 are presented in Figures $5 \mathrm{a}$ and $5 \mathrm{~b}$, respectively. In each case, all specimens exhibited nonlinearity prior to a sudden force drop (corresponding to the assumed onset of delamination growth). For specimens with longer insert lengths, the extent of nonlinearity prior to the force drop was more pronounced and the force drop was typically more gradual, especially in the case of the plate 2 specimens. The nonlinear response of ECT specimens is consistent with previous observations $[7,9,10,14,16]$.

\subsection{Apparent $G_{I I I c}$ testing and observed delamination growth}

Data from the group 1 and 2 specimens from each plate were used to compute apparent $G_{\text {IIIc }}$ following the procedure described in Sec. 3.2. A summary of all apparent $G_{I I I c}$ values versus normalized crack length, $a / b$, is presented in Fig. 6. For comparison, data from the previous study using the same material [8] are also included. The data from these two studies are consistent, indicating that, over the range of $a / b$ considered in this study, the apparent value of $G_{I I I c}$ is relatively constant in comparison to data obtained over a larger range of $a / b[8,10,14]$. The only exception is specimens from plate 1, group 2, where apparent $G_{I I I c}$ was the lowest for the intermediate insert lengths. Interestingly, if one was to restrict measurement of apparent $G_{\text {IIIc }}$ to essentially the same range used in this study, (i.e., $a / b=0.1$ to 0.4 ) then the data presented in $[8,10,14]$ also appears somewhat independent of the insert length. However, while it is possible that the apparent toughness obtained from this shorter range of insert lengths could be a material property, this is not at all clear. It is equally possible that whatever mechanism is responsible for the geometry-dependence of the apparent toughness at longer insert lengths simply occurs to the same degree in all specimens over the range $a / b=0.1$ to 0.4 . A finding of this type was made in a parallel study using mode III split beam-type tests [17]. Thus, the question remains as to why apparent $G_{I I I c}$ tends to increase with values of $a / b$ beyond 0.4 . The answer to this question should provide insight as to whether the average value of apparent $G_{I I I c}$ obtained from specimens within the current range of $a / b$ represents a true material property.

To further explore the above observations, the ECT specimens were examined by performing nondestructive and destructive evaluations. Specimens used to measure apparent $G_{\text {IIIc }}$ (see Table 1) were C-scanned using the procedures described in Sec. 3.3. Figure 7 depicts an example of ultrasonic time-of-flight images for specimens with the shortest, intermediate, and longest insert lengths (plate 1 , group $1, a / b=0.118,0.268,0.358$ ). In Fig. 7 , a darker shade of gray corresponds to a through-thickness location of the detected feature that is closer to the back surface. The light gray region on the bottom of each image corresponds to the location of the insert, and the dark gray region at the top corresponds to the signal reflected from the back surface. Examination of the time-of-flight data from the specimens in Fig. 7 shows that macroscopic delamination advance did not occur at the midplane as intended. Rather, for all specimens, delamination advance occurred one ply interface below the midplane at the 90/45 
interface. For a few specimens (e.g., specimens with $a / b=0.268$ or 0.358 in Fig. 7), some delamination advance was observed at the midplane; however, the extent of this advance was small relative to the extension along the 90/45 interface. A few specimens exhibited limited advance at the interface above the midplane at the 45/90 interface. Overall, the delamination advance observed in this study is different from what has typically been assumed to occur in ECT tests.

To both corroborate and further understand the nature of delamination growth observed in the $\mathrm{C}$-scan images, specimens were sectioned and examined using an optical microscope. Fig. 8 shows an image of a sectioned specimen with $a / b=0.358$ (corresponding to the bottom specimen in Fig. 7) taken at the intersection of planes A-A and B-B defined in Fig. 1. The various gray bands correspond to individual plies as noted on the left side of the figure. As evidenced by this image and being consistent with the $\mathrm{C}$-scan data in Fig. 7, macroscopic delamination advance took place at the 90/45 interface, with only very limited advance occurring at the midplane. In addition to delamination, a large number of angled intralaminar cracks were visible through the midplane $90^{\circ}$ plies and terminating at the adjacent $45^{\circ}$ plies.

The observed intralaminar cracks provide a potential explanation for the presence of vertical lines (aligned with the $90^{\circ}$ direction) inside the delaminated regions seen in C-scan data in Fig. 7. Interestingly, without performing destructive inspection, the presence of these vertical lines gives the C-scan data an appearance of delamination growth occurring at the midplane, 90/90 interface. Overall, the above observations were consistent between specimens from plate 1 (90/90 interface) and plate $2(+88 /-88$ interface). Thus, the attempt to reduce fiber nesting by slightly misaligning the midplane plies (see Sec. 2) had little or no effect on the observed damage state.

\subsection{Damage progression testing}

The results in the preceding section illustrate that the current ECT specimens exhibit extensive intralaminar matrix cracking in the midplane plies and macroscopic delamination at an unintended ply interface (90/45) away from the midplane. Given these observations, the remainder of this study was conducted to address the following two questions:

1) Does matrix cracking initiate prior to or during macroscopic delamination advance?

2) What mechanisms cause (or contribute to) the observed intralaminar matrix cracking?

To answer question 1 , one specimen $(a / b=0.185)$ from the third group of plate 2 was incrementally tested to different force levels between $P_{N L}$ and macroscopic delamination advance and ultrasonically inspected after each loading cycle (see description in Section 3.4). The resulting C-scan images are presented in Fig. 9. At $P_{N L}$ no damage was observed, and the C-scan image was essentially identical to the image obtained prior to testing. As the force level was increased beyond $P_{N L}$ to $82 \%, 87 \%$, and $91 \%$ of $P_{\max }$ (Figs. $9 \mathrm{~b}-\mathrm{d}$, respectively), changes were detected in the reflected ultrasonic signal in the region just ahead of the Teflon insert. This appears as the thin black band at the delamination front in Figs 9b-d, within which no reflected signal was obtained. Subsequently, it will be shown that this ultrasonic attenuation was caused by the presence of intralaminar matrix cracks bisecting the midplane plies.

At $95 \% P_{\max }$ (Fig. 9e) the C-scan image indicates that macroscopic delamination advance in this specimen is at the 90/45 and 90/90 interfaces. Fig. 9f is a post-test scan, i.e., after the final increment of loading and the associated sudden force drop. Here, the delamination has extended 
primarily at the 90/45 interface, with a limited amount of delamination extension observable at the 90/90 interface. Sectioning and optical microscopy of this specimen along planes A-A and B$\mathrm{B}$ further confirmed that the damage was essentially identical to the post-test damage that was observed in specimens used to measure apparent $G_{\text {IIIc }}$ (Fig. 8).

To answer question 2, several remaining specimens (see Table 1) were tested either to $P_{N L}$ or 95\% $P_{\max }$, ultrasonically inspected, and then sectioned for optical microscopy. Typical results obtained from this evaluation are presented in Fig. 10. The left column in Fig. 10 shows C-scan images obtained after testing and prior to sectioning, while the right column depicts a representative micrograph taken along plane B-B from each respective specimen. The micrographs in Fig. 10 are termed "representative" as the damage seen in each image was repeated with relatively constant frequency across the length of each specimen. In each image on the right, the gray band in the middle corresponds to the resin rich region that typically forms ahead of the insert during fabrication. Optical inspection along plane B-B of the specimens tested to $P_{N L}$ (Fig. 10a) revealed a large number of angled microcracks in the resin rich region. In the specimen tested to $95 \% P_{\max }$ (Fig. 10b), the total number of microcracks across the length $l$ (the frequency of the resin microcracks) increased. In addition, a large number of the microcracks appeared to have extended intralaminarly through the two midplane $90^{\circ}$ plies, terminating at the surrounding $45^{\circ}$ plies. Generally, the microcracks in the resin rich region and the intralaminar cracks through the midplane plies were oriented at approximately $45^{\circ}$ to the midplane. Any significant deviations from this orientation appeared to have been caused by local variations in microstructure, such as voids, resin rich regions or nested fibers.

As may be observed in Fig. 10b C-scan image, in some cases a small amount of midplane delamination growth occurred as the angled intralaminar cracks in the resin rich region extended into intralaminar cracks through the $90^{\circ}$ plies. More significant, however, is that upon reaching the $45^{\circ}$ plies, some of these intralaminar cracks turned and extended interlaminarly as delaminations along the 90/45 interface. Fig. 10c shows that advance and interconnection of these delaminations along the 90/45 interface likely resulted in the primary mode of macroscopic advance and confirms that this is the event corresponding to the observed force drop at $P_{\max }$.

To gain further insight into the processes discussed above, it is useful to consider results in the literature for cracked geologic materials, homogeneous materials, and for delaminated unidirectional composite laminates subjected to anti-plane shear loadings. In the first two cases, it has been well-established that crack advance does not occur as an essentially planar advance of the original crack front, but rather as a series (or echelon) of cracks that initiate and grow at a $45^{\circ}$ angle to the original crack plane, where the angle of inclination is oriented perpendicularly to the direction of maximum tensile stress (e.g., [18-23]). This discontinuity in crack surface evolution is often described as a combination of crack front segmentation and rotation [24-26]. Consistent with all of the experimental results in these references, a recent model [26] suggests that there is a linear instability that will cause an initially planar mode III crack in a homogenous material to always advance in this manner. Similar results were postulated to occur in unidirectional laminated composites when there was a correspondence between the fiber direction and the intended direction of mode III advance [27]. This was recently found to be the case in companion and collaborative works $[17,28]$. Here, it is shown that the evolution of damage, beginning with $45^{\circ}$ microcrack initiation in the resin rich region and progressing to $45^{\circ}$ intralaminar crack growth through the midplane plies prior to any macroscopic delamination advance, occurs similarly to the ECT specimens studied herein when unidirectional coupons are 
tested in anti-plane shear. Thus, the current findings and the results of [17,28] for unidirectional composites are all locally consistent with those for homogeneous and geologic materials.

\subsection{Fracture mechanisms in the ECT specimens and assessment of the test method}

The C-scan and fractographic data presented in the previous two sections suggest that the overall sequence of events that occur on plane B-B at the end of the Teflon insert in ECT specimens progresses in three general stages. Figure 11 illustrates the overall process. In Stage 1, microcracking initiates in the resin rich region ahead of the insert. In the current study, these microcracks were present when the specimen's response deviated from linearity (i.e., at $P \cong P_{N L}$ ). However, it is likely that microcracking must be present in a critical amount in order to manifest itself in the specimen's force versus deflection response. Thus, although not confirmed in the current investigation, the exact instance of microcrack initiation likely occurs prior to $P_{N L}$. As previously described, these microcracks are oriented at approximately $45^{\circ}$ to the specimen's midplane and are orthogonal to the direction of the of the maximum tensile stress associated with the $K_{I I I}$ field, where $K_{I I I}$ is the mode III stress intensity factor at the insert. This stress decomposition is shown in Fig. 12. During Stage 2, frequency of microcracking increases, and some microcracks extend through the midplane plies and into the adjacent interface, as the force is increased from $P_{N L}$ to a value approaching $P_{\max }$. This process proceeds analogously to that originally described by [20] for homogeneous materials. Initial microcracks occur due to irregularities along the insert front. This relieves the stress locally but increases the likelihood of another crack developing in the vicinity. The overall spacing of the cracks should become essentially uniform and can be approximated using a shear lag analysis, similar to that which has been considered for microcracking associated with mode II loading [29]. Because the two midplane plies have their fiber orientations aligned with the direction of macroscopic advance, microcrack initiation and extension during this stage is essentially unconstrained by the fibers (see Fig. 12). Stage 2 concludes when the microcracks reach the more constraining fiber orientation associated with the $45^{\circ}$ plies and interlaminar delamination initiates at the 90/45 interface, as shown in Fig. 10b. Stage 3 then commences as the force approaches $P_{\max }$. Here, delaminations at the 90/45 interface and, to a lesser extent at the 90/90 interface, link together. Macroscopic advance, as shown in Figs. 9e and 10c, occurs when the force reaches $P_{\max }$. The final outcome is a fully three-dimensional, relatively rough surface with a "factory roof" [25] profile that the geologic fracture literature refers to as echelon cracking [18,21,23] and the literature on fracture of homogeneous materials refers to as being comprised of "lances" $[19,30]$, "river lines" [24] and/or "facets" [26].

In view of the above discussion, the presence of extensive intralaminar cracking in the midplane plies prior to onset of delamination clearly invalidates the assumptions associated with computation of $G_{\text {IIIc }}$ using Eq. 2. As a consequence, the data presented in Fig. 6 does not correspond to the true measure of mode III initiation fracture toughness, but instead represents a "structural" response of the ECT specimen to the applied mode III loading. Given that all ECT tests reported in the literature use a similar stacking sequence (i.e., having $90^{\circ}$ plies bounding the insert), it is possible that the commonly observed dependence of apparent $G_{I I I c}$ on edge delamination length is, in fact, due to the occurrence of mechanisms similar to those observed herein. Further, as the microcracks initiate prior to macroscopic delamination advance, it follows that the relatively constant value of apparent $G_{I I I c}$ observed earlier for the range $a / b=0.1$ to 0.4 cannot be considered a material property. Thus, it is concluded from these findings that the ECT 
test with its current stacking sequence is unsuitable for measuring mode III fracture toughness in laminated FRP composites.

\subsection{Broader implications for shear-driven delamination in tape laminates}

In many respects, the fracture mechanisms observed in ECT specimens are similar to those observed in unidirectional mode II fracture toughness test specimens. In mode II, $45^{\circ}$ microcracks also initiate ahead of the insert, within the resin rich region at the specimen's midplane. These microcracks arise due to the resolved principal tensile stresses that are associated with the applied in-plane shear loads, similar to microcrack development in the ECT specimens. However, in mode II, the microcracks are inclined in the direction of intended macroscopic advance, and their through-thickness growth (i.e., into the bounding plies) is constrained by the fibers of the bounding plies. Thus, it is energetically more favorable for these microcracks to remain within the resin rich region at the midplane; with increasing load, these microcracks link and coalesce and create what is macroscopically observed to be mode II delamination [29]. Thus, strictly speaking, "mode II delamination" in laminated FRP composites is a series of mode I events, but the fact that the fibers constrain mode I intralaminar crack advance means that a useful engineering quantity is obtained from these tests [31]. In the case of the ECT specimens however, the plies bounding the insert are oriented such that the intended delamination growth direction would follow the direction of the fibers of these plies. This is intended to make the test consistent with the unidirectional tape specimens used for measuring mode I, mode II and mixed-mode I/II fracture toughness. However, by applying such a ply orientation to the ECT specimen, the microcracks resulting from the resultant tensile stresses (from the mode III shear loading) are not contained by the bounding plies. Thus, rather than coalescing into a macroscopic delamination, as is the case in mode II loading, the microcracks simply grow transversely through these bounding midplane plies. This intralaminar crack growth continues until a ply is reached that is able to terminate (constrain) this process. In the ECT specimens this happens at the 90/45 ply interfaces above and below the midplane plies.

The preceding discussion raises the question of whether it is possible that a different choice of stacking sequence for the ECT specimen could be used such that the plies bounding the midplane would constrain the microcracks to the midplane interlaminar region. Such an approach could potentially produce a value of $G_{I I I c}$ that is independent of delamination length for some range of bounding ply angles. That is, this would provide a mode III test that would produce a useful engineering quantity, similar to the approach that has been adopted in mode II. At present, the determination of appropriate bounding ply angles would need to be established experimentally. In addition, this may allow for a correspondence to be made between mode II and mode III toughness tests: specifically, to determine whether there is a certain range of bounding ply angles, measured with respect to the direction of delamination advance, that will constrain delamination growth to occur along the intended interface in both modes II and III. While this would surely be an important development in an overall engineering approach to predict delamination growth, note that it also brings to light many of the deficiencies in our understanding of the true details of delamination advance in both modes II and III, and highlights the need for further study in order to develop a mechanistically accurate approach to both delamination growth characterization and its prediction. 


\section{Concluding Remarks}

Edge crack torsion specimens made with preimplanted inserts between two slightly different ply interfaces (+88/-88 and 90/90 ply interfaces) were manufactured from IM7/8552 prepreg tape. Specimens of each layup contained normalized insert lengths ranging from 0.10 to 0.35 . A generally accepted procedure for measuring $G_{I I I c}$ using these specimens was followed, and both specimen types produced essentially identical results. Apparent $G_{I I I c}$ was found to be largely independent of the insert length over the range considered, and measured values were comparable with previously reported values for the same material system. However, ultrasonic and fractographic inspections revealed that delamination advance in all specimens unintentionally took place primarily at the $90 / 45$ ply interface, one ply below the midplane. It was found that a series of microcracks developed prior to macroscopic delamination advance within the resin rich region ahead of the insert. These microcracks were observed to develop into intralaminar cracks that bisected the two plies bounding the midplane. Their growth was arrested at the adjacent 90/45 interface. A portion of these cracks then changed direction and continued advancing as interlaminar delaminations. Linkage of these delaminations resulted in the observed macroscopic delamination growth.

It is clear from these results that delamination advance in ECT specimens occurs quite differently than that which is assumed in any of the commonly employed methods of data reduction. Thus, the apparent value of mode III toughness that is extracted from the ECT test does not reflect the mechanics or physics of the processes that occur, and there is no reason to expect that such results will be valid. This explains the commonly observed dependence of measured $G_{I I I c}$ on insert length. Moreover, the above findings confirm that ECT specimens in their current form, with the plies that bound the insert oriented at or near to $90^{\circ}$, are unsuitable for measuring $G_{I I I c}$ associated with mode III delamination growth onset. To address this deficiency, it has been suggested that alternative ECT stacking sequences may be possible that constrain the interlaminar microcracks at the midplane from growing intralaminarly. Tests of these specimens may provide a mode III toughness that is independent of insert length, and which could therefore be interpreted in a manner that is analogous to what is currently done for mode II. More broadly, this approach may be extended to an assessment of whether there is a certain range of bounding ply angles, measured with respect to the direction of delamination advance, that will constrain delamination growth to occur along the intended interface in both modes II and III. This would provide a consistent approach for characterizing both modes of shear-driven growth.

\section{References}

1. American Society for Testing and Materials. Standard Test Method for Mode I Interlaminar Fracture Toughness of Unidirectional Fiber-Reinforced Polymer Matrix Composites, ASTM Standard D5528-01; 2008.

2. Davidson, BD. Determination of the mode II interlaminar toughness of unidirectional fiber reinforced polymer matrix composites using the end-notch flexure (ENF) test, ASTM Work Item WK-37680; 2012.

3. American Society for Testing and Materials. Standard Test Method for Mixed Mode I-Mode II Interlaminar Fracture Toughness of Unidirectional Fiber Reinforced Polymer Matrix Composites, ASTM Standard D6671-06; 2006. 
4. Donaldson SL. Mode III interlaminar fracture characterization of composite materials. Compos Sci Technol 1988; 32(3):225-49.

5. Robinson P, Song DQ. A new mode III delamination test for composites. Adv Compos Lett 1992; 1:160-164.

6. Sharif F, Kortschot MT, Martin RH. Mode III delamination using a split cantilever beam. In: Martin RH, editor. Composite materials: fatigue and fracture - Fifth Volume, ASTM STP 1230. Philadelphia: American Society for Testing and Materials; 1995, p. 85-99.

7. Lee SM. An edge crack torsion method for mode III delamination fracture testing. J Compos Technol Res 1993; 15(3):193-201.

8. Ratcliffe JG. Characterization of the edge crack torsion (ECT) test for mode III fracture toughness measurement of laminated composites. NASA-TM-2004-213269; 2004.

9. de Morais AB, Pereira AB, de Moura MFSF, Magalhães AG. Mode III interlaminar fracture of carbon/epoxy laminates using the edge crack torsion (ECT) test. Compos Sci Technol 2009; 69(5):670-676.

10. Li X, Carlsson LA, Davies P. Influence of fiber volume fraction on mode III interlaminar fracture toughness of glass/epoxy composites. Sci Technol 2004; 65(2):295-300.

11. Greenhalgh, ES, Rogers, C and Robinson, P. Fractographic Observations on Delamination Growth and the Subsequent Migration Through the Laminate. Compos Sci Technol 2009; 69(14):2345-2351.

12. de Morais AB, Pereira AB, de Moura AFSF. Mode III interlaminar fracture of carbon/epoxy laminates using the Six-Point Edge Crack Torsion (6ECT). Compos Part A 2011; 42(11):1793-1799.

13. Pennas D, Cantwell WJ, Compston P. The influence of strain rate on the mode III interlaminar fracture of composite materials. J Compos Mater 2007; 41(21):2595-614.

14. Browning G, Carlsson LA, Ratcliffe JG. Modification of the edge crack torsion specimen for mode III delamination testing. Part II - experimental study. J Compos Mater 2011; 45(25):2633-2640.

15. Hexcel Corporation. HexPly ${ }^{\circledR} 8552$ Product Data Sheet - http://hexcel.com; 2007.

16. Marat-Mendes R, de Freitas M. Characterization of the edge crack torsion (ECT) test for the measurement of the mode III interlaminar fracture toughness. Eng Fract Mech 2009; 76(18):2799-2809.

17. Johnston AL, Davidson BD, Simon KK. Assessment of split-beam-type tests for mode III delamination toughness determination. Int J Fract 2013, DOI: 10.1007/s10704-013-9897-1.

18. Roering $\mathrm{C}$. The geometrical significance of natural en-echelon crack-arrays. Tectonophysics 1968; 5(2):107-123.

19. Knauss WG. An observation of crack propagation in anti-plane shear. Int J Fract Mech 1970; 6(2):183-187.

20. Palaniswamy K, Knauss WG. On the problem of crack extension in brittle solids under general loading. Mech Today 1978; 4(3):87-148. 
21. Pollard DD, Segall P, Delaney PT. Formation and interpretation of dilatant echelon cracks. Geol Soc Am Bull 1982; 93(12):1291-1303.

22. Li S, He T, Teng C, Zheng X, Viktor K. Theoretical and experimental study of 3-D initial fracture and its significance to faulting. Earthq Sci 2011; 24(3):283-298.

23. Goldstein RV, Osipenko NM. Structures of fracture near a longitudinal shear main crack. Proceedings of the $19^{\text {th }}$ European conference on fracture, Kazan, Russia; Aug 26-31, 2012.

24. Hull D. Tilting cracks: the evolution of fracture surface topology in brittle solids. Int J Fract 1993; 62(2):119-138.

25. Lin B, Mear ME, Ravi-Chandar K. Criterion for initiation of cracks under mixed-mode I + III loading. Int J Fract 2010; 165(2):175-188.

26. Leblond J-B, Karma A, Lazarus V. Theoretical analysis of crack front instability in mode I + III. J Mech Phys Solids 2011; 59(9):1872-1887.

27. Trakas K, Kortschot MT. The relationship between critical strain energy release rate and fracture mode in multidirectional carbon-fiber/epoxy laminates. In: Armanios EA, editor. Composite materials: fatigue and fracture- Sixth Volume, ASTM STP 1285. Philadelphia: American Society for Testing and Materials; 1997, p. 283-304.

28. Johnston AL, Davidson BD, Intrinsic coupling of near-tip matrix crack formation to mode III delamination advance. Int J Solids and Structures 2013. In Review.

29. Lee SM. Mode II delamination failure mechanisms of polymer matrix composites. J Mater Sci 1997; 32(5):1287-1295.

30. Sommer E. Formation of fracture 'lances' in glass. Eng Fract Mech 1969; 1(3):539-46.

31. O'Brien TK. Composite Interlaminar Shear Fracture Toughness, G $\mathrm{GIc}_{\mathrm{Ic}}$ : Shear Measurement of Sheer Myth? Composite Materials: Fatigue and Fracture, Seventh Volume, ASTM STP 1330, R.B. Bucinell, Ed., American Society for Testing and Materials; 1998, p. 3-18. 
Table 1. Summary of the test matrix.

\begin{tabular}{|l|l|l|l|}
\cline { 2 - 4 } \multicolumn{1}{c|}{} & Group 1 & Group 2 & \multicolumn{1}{c|}{ Group 3 } \\
\hline Plate 1 & $G_{I I I c}$ tests & $G_{I I I c}$ tests & $\begin{array}{l}-2 \text { specimens tested to } P_{N L} \\
-4 \text { specimens tested to } P=95 \% P_{\max }\end{array}$ \\
\hline Plate 2 & $G_{I I I c}$ tests & $G_{I I I c}$ tests & $\begin{array}{l}-1 \text { specimen tested } 6 \text { times between } P_{N L} \text { and } P_{\max } \\
-5 \text { specimens tested to } P=95 \% P_{\max }\end{array}$ \\
\hline
\end{tabular}

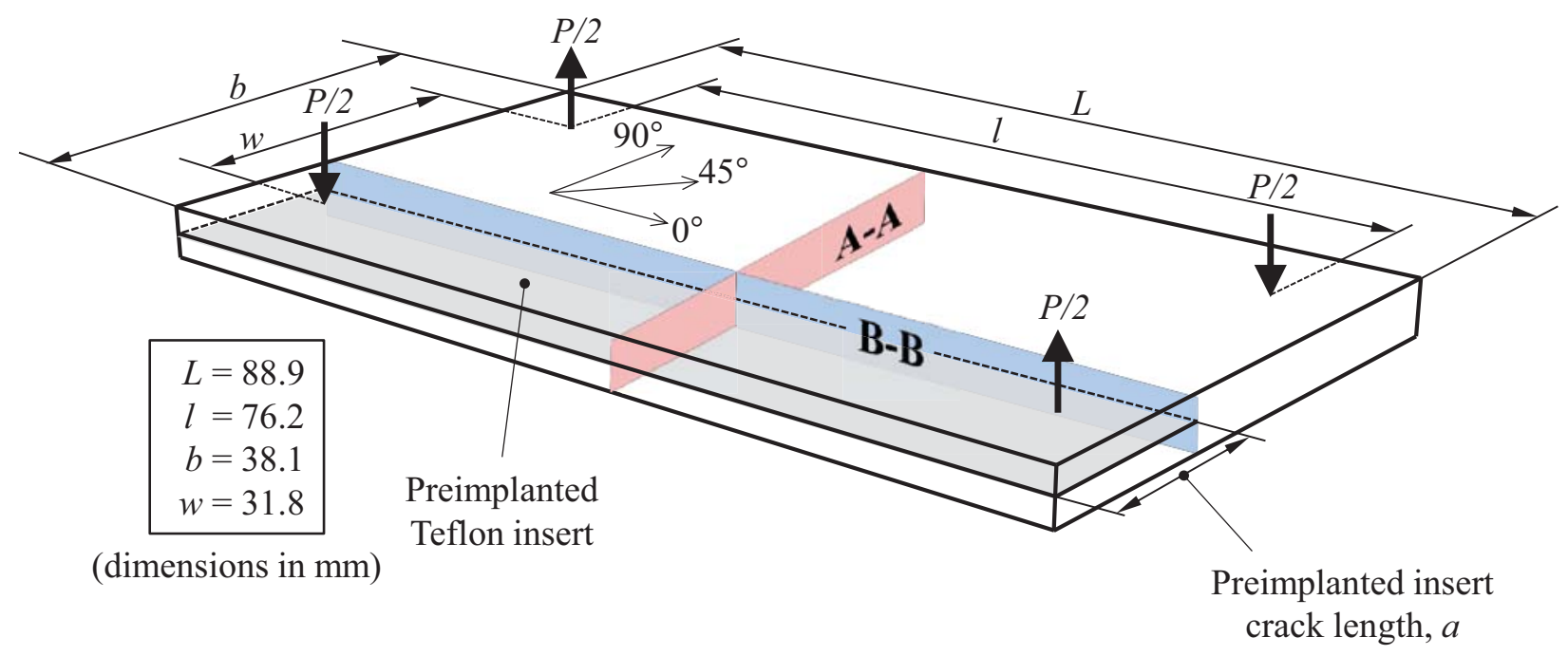

Figure 1. The ECT test geometry. Planes A-A and B-B define cuts made for optical examinations. 


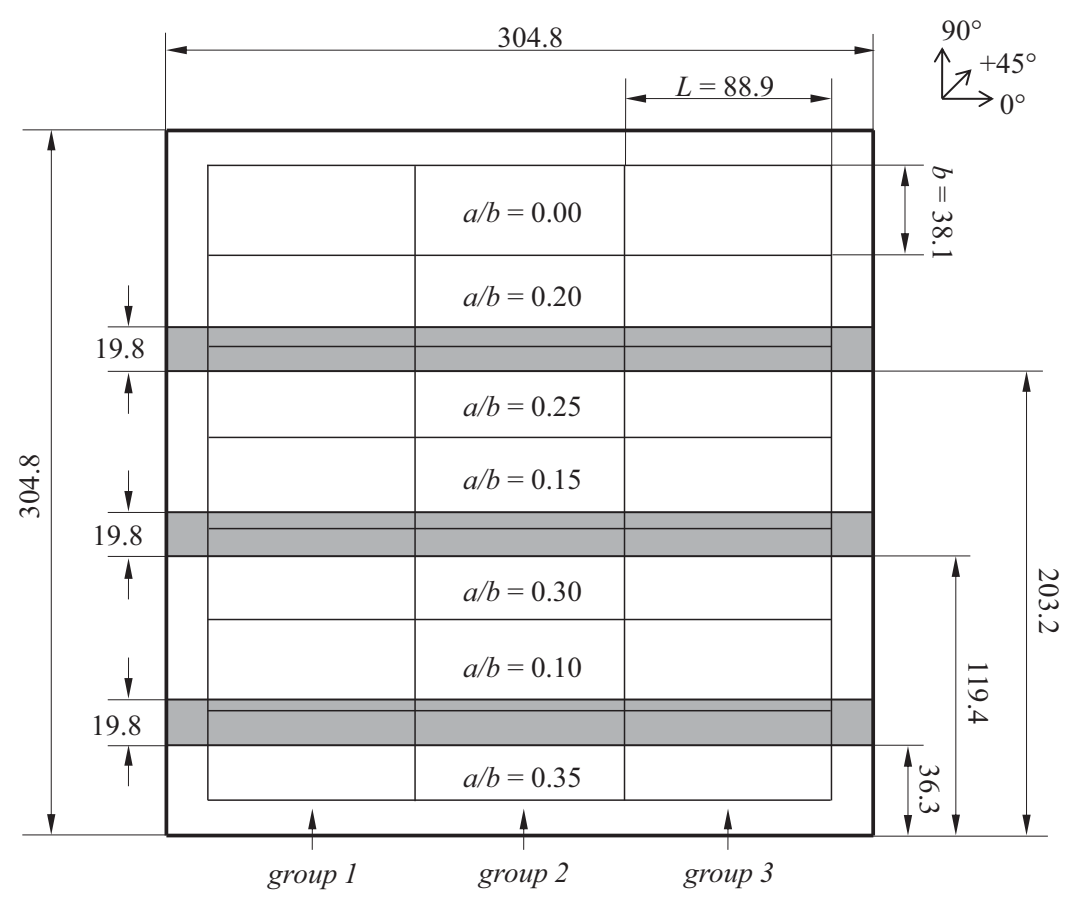

(all dimensions in $\mathrm{mm}$, not to scale)

Figure 2. Typical ECT specimen plate layout. The shaded regions correspond to the preimplanted Teflon inserts at the midplane.

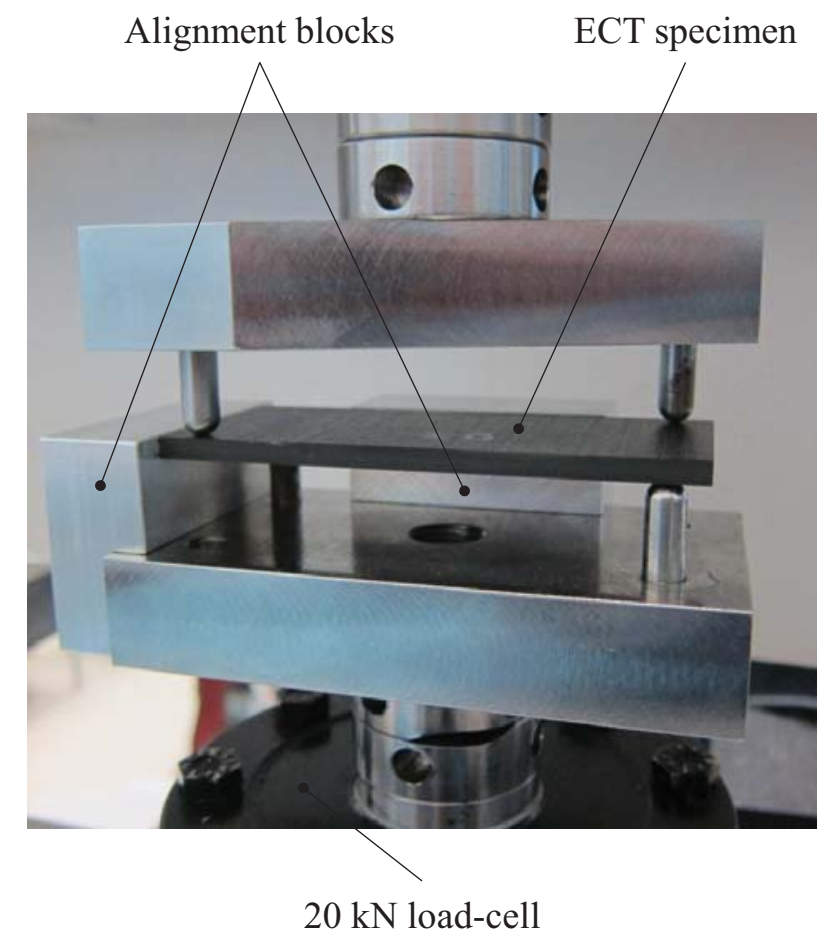

Figure 3. ECT test setup (note: alignment blocks are removed prior to testing). 


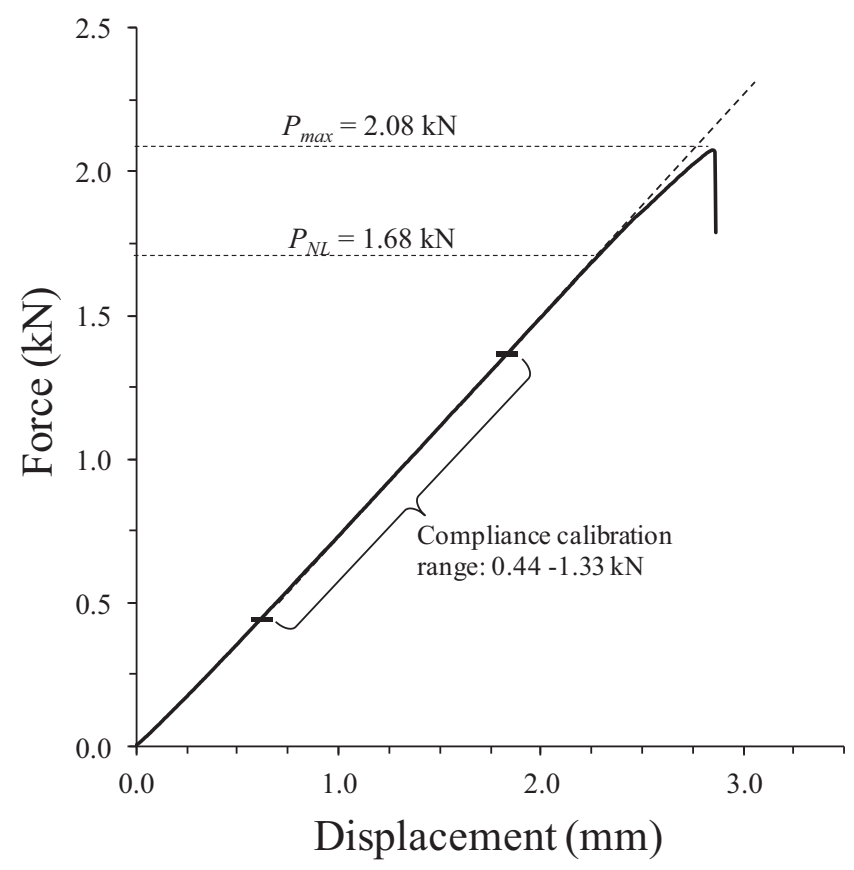

Figure 4. Typical force-displacement response of an ECT specimen.

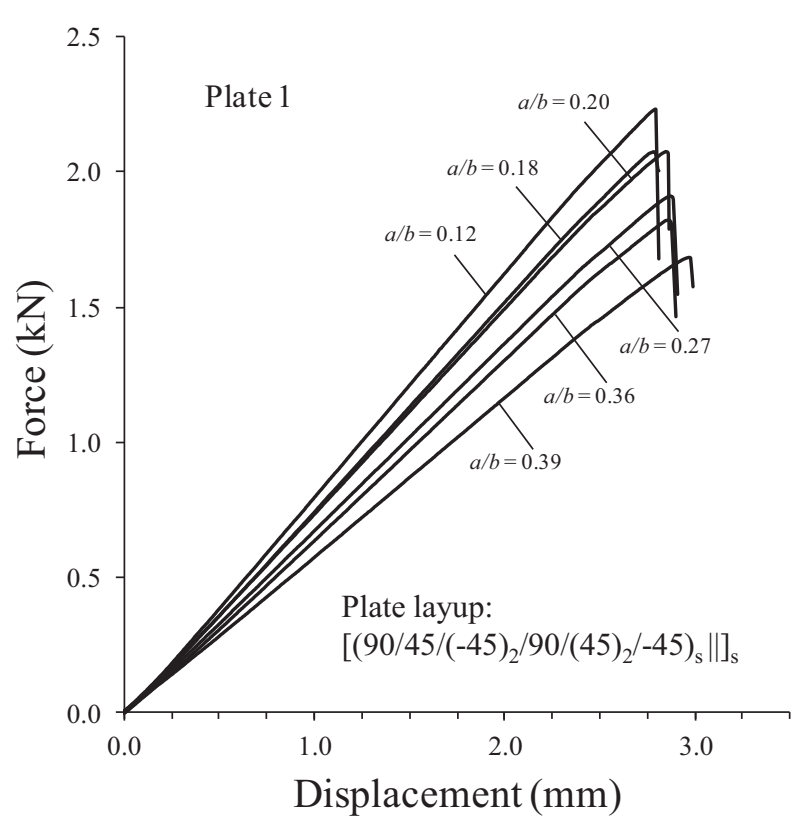

(a)

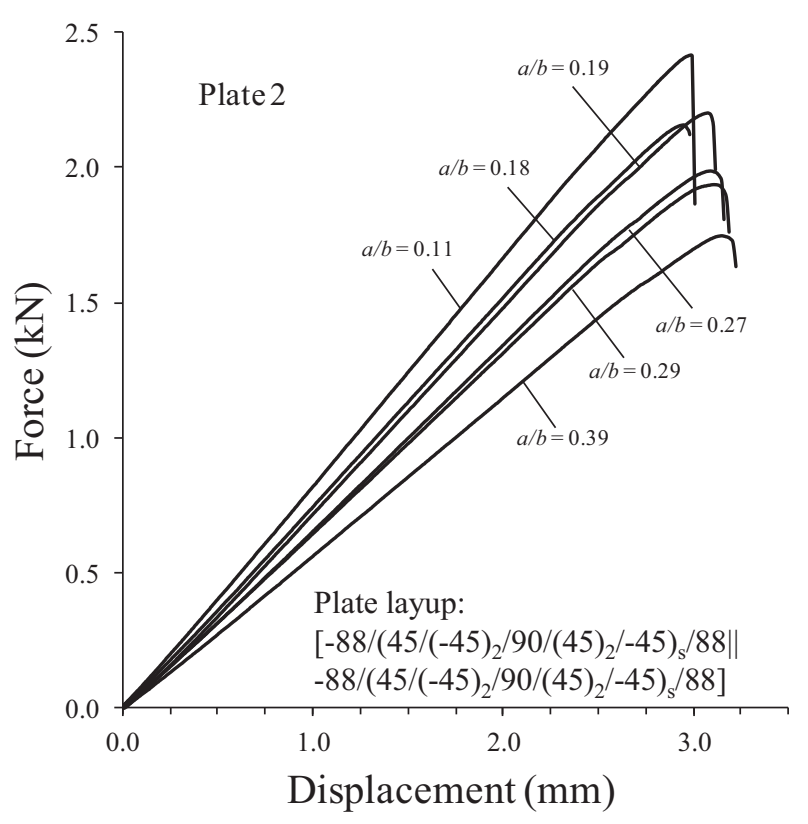

(b)

Figure 5. Force-displacement data from (a) plate 1 and (b) plate 2 specimens. 


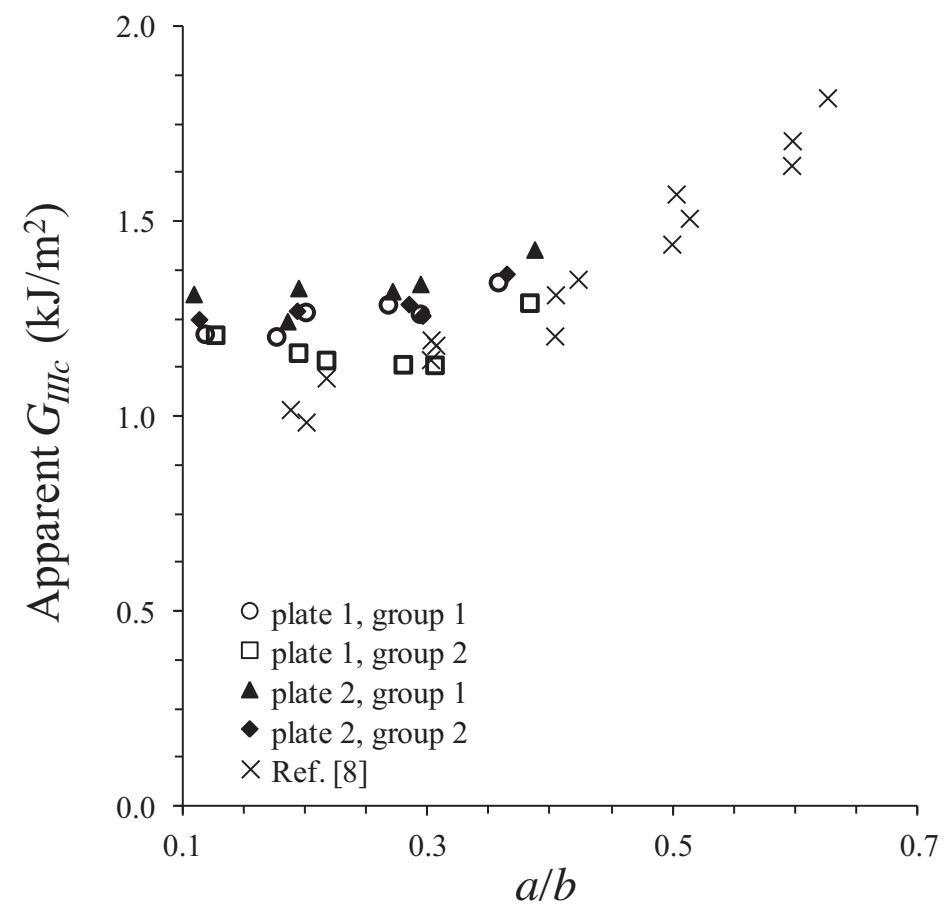

Figure 6. Apparent $G_{I I I c}$ versus normalized crack length.
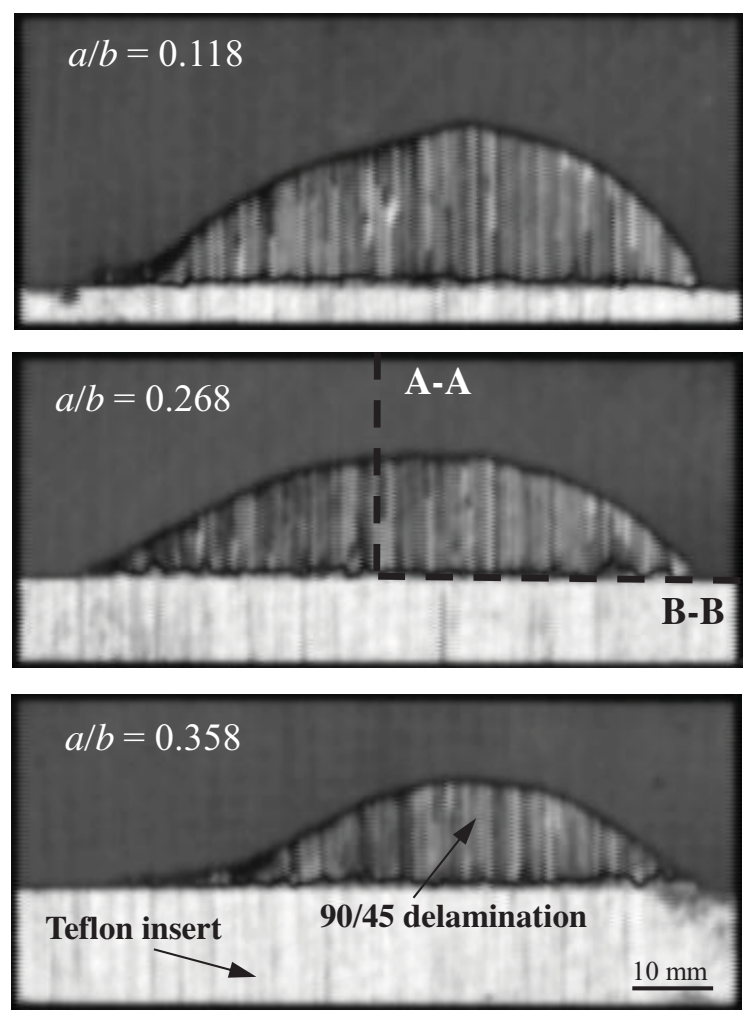

Figure 7. Typical C-scans of specimens used to compute apparent $G_{I I I c}$ (plate 1, group 1). 


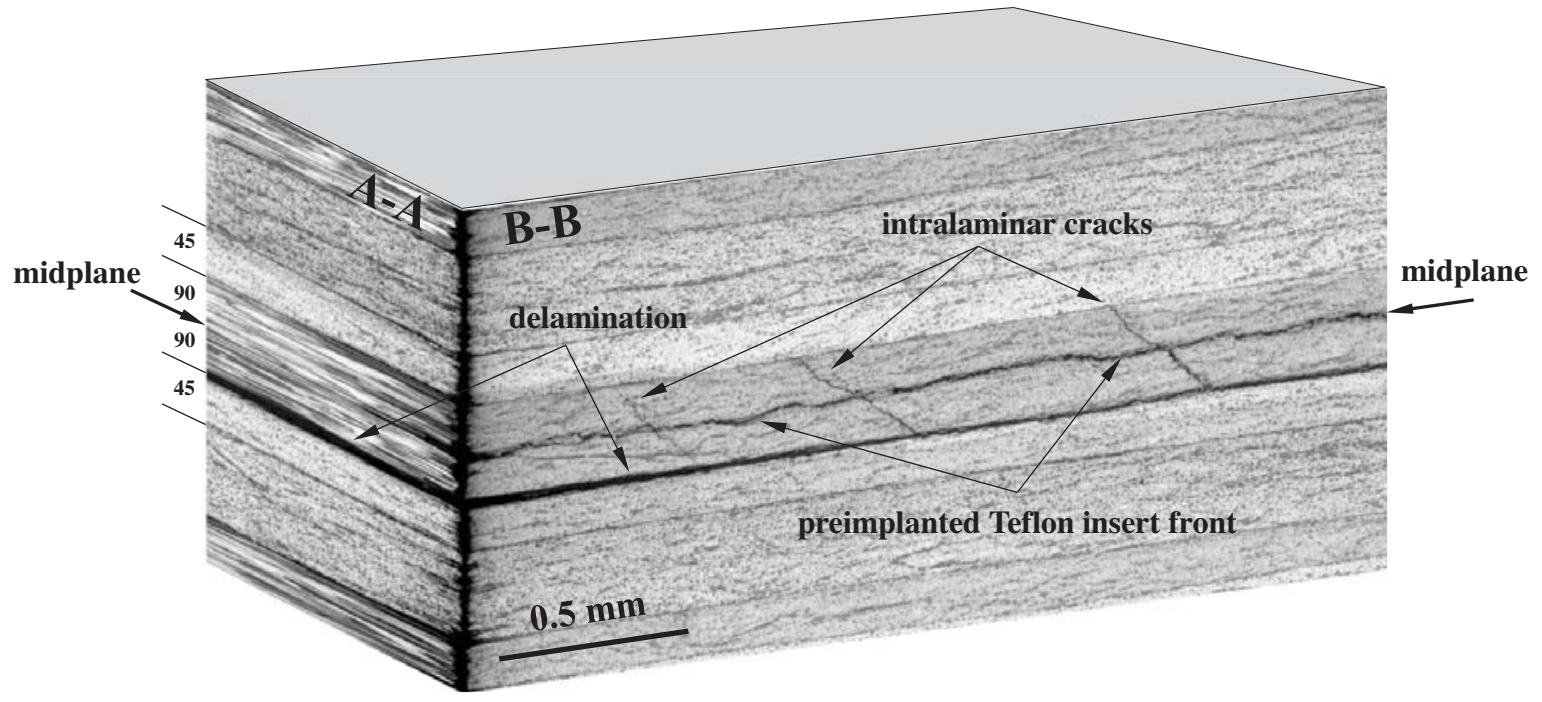

Figure 8. Optical image of specimens used to compute apparent $G_{I I I c}$ at the intersection of planes A-A and B-B (plate 1, group $1, a / b=0.358$ ).

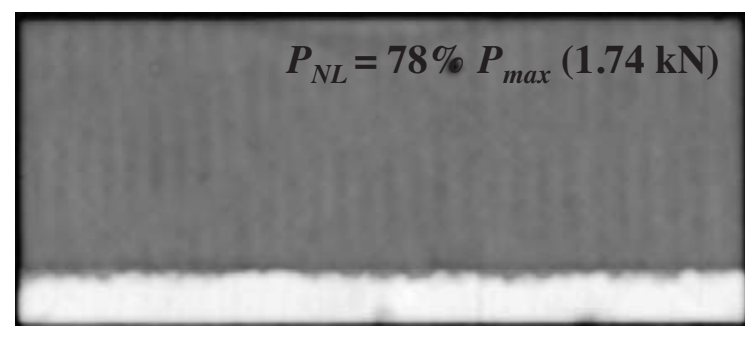

(a)

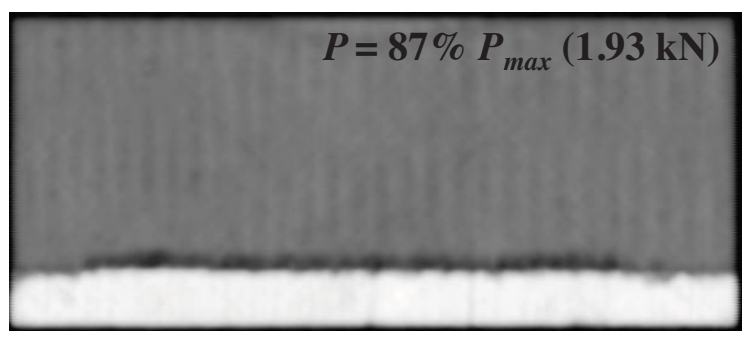

(c)

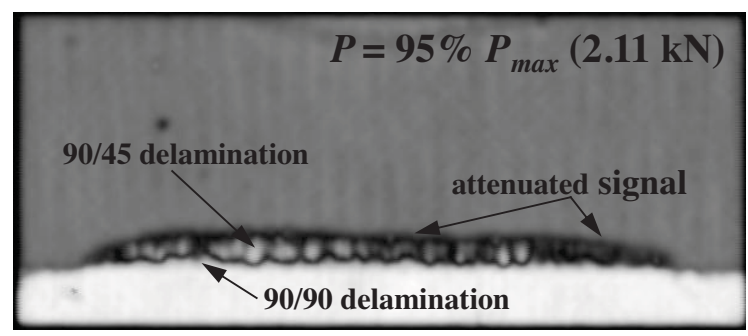

(e)

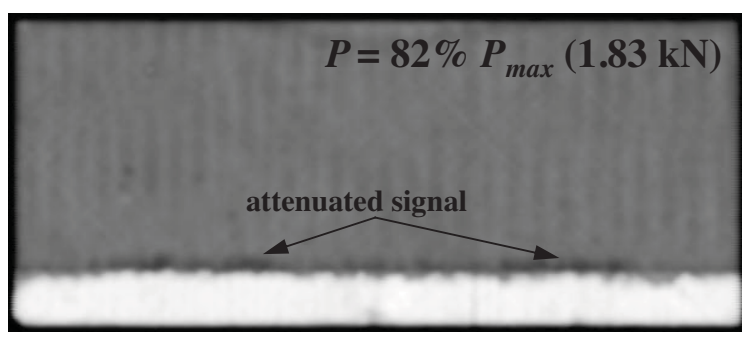

(b)

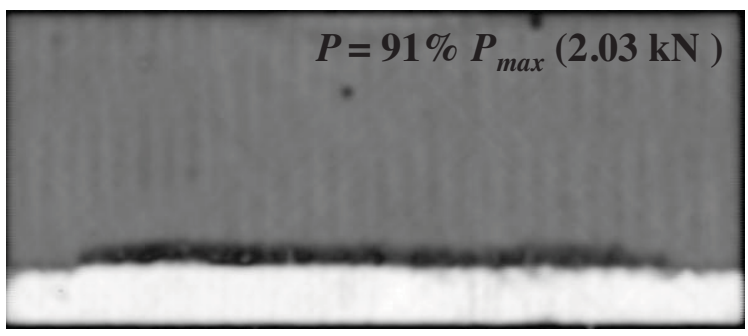

(d)

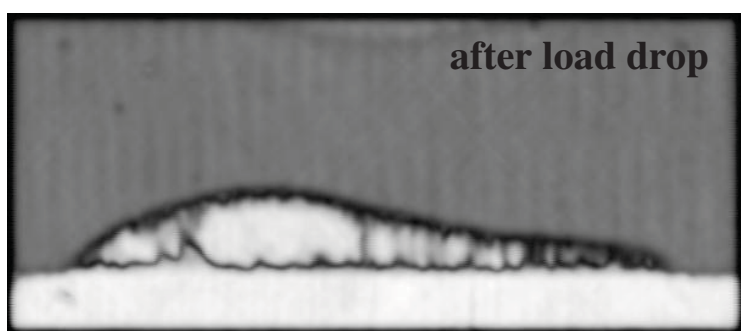

(f)

Figure 9. C-scans from progressive loading of specimen with $a / b=0.185$ (plate 2 , group 3 ). 
C-scan

(a)

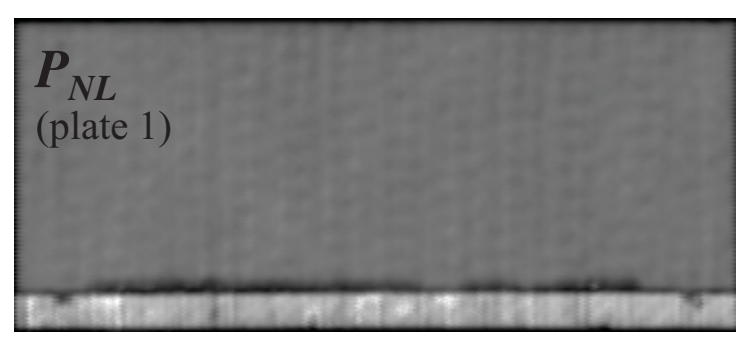

(b)
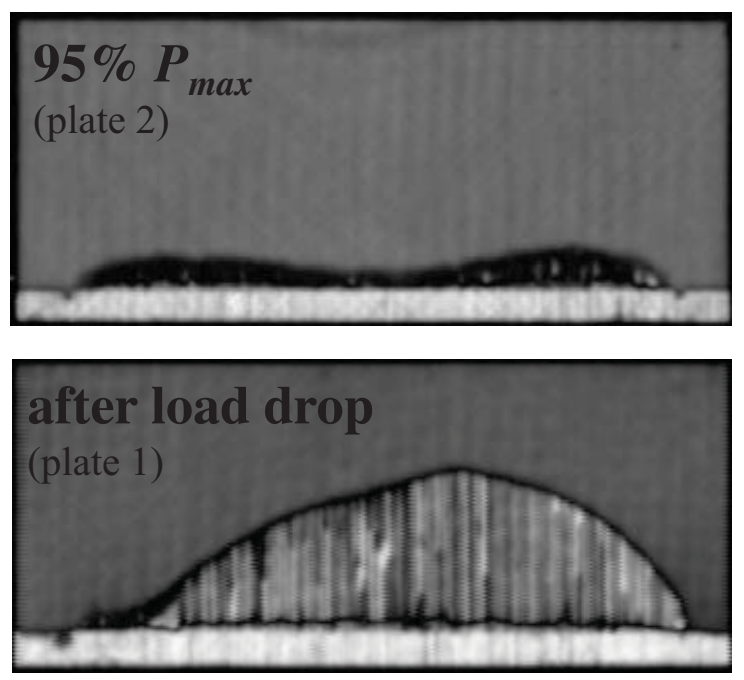

Section B-B
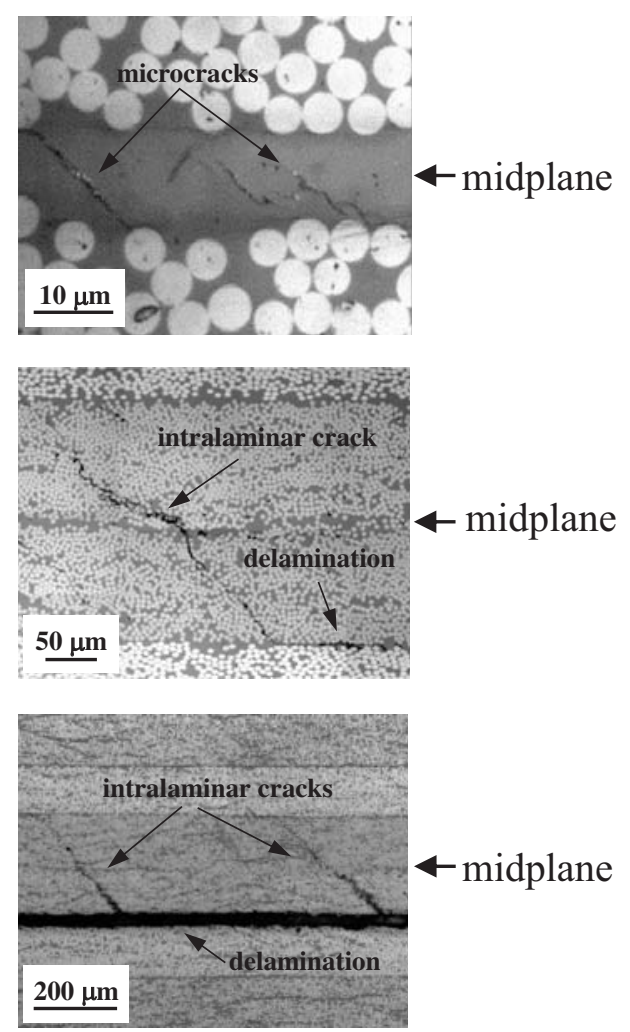

Figure 10. C-scan and micrograph (plane B-B) of specimen loaded to (a) $P_{N L}$, (b) $95 \% P_{\max }$, and (c) delamination growth $(a / b=0.10)$. 


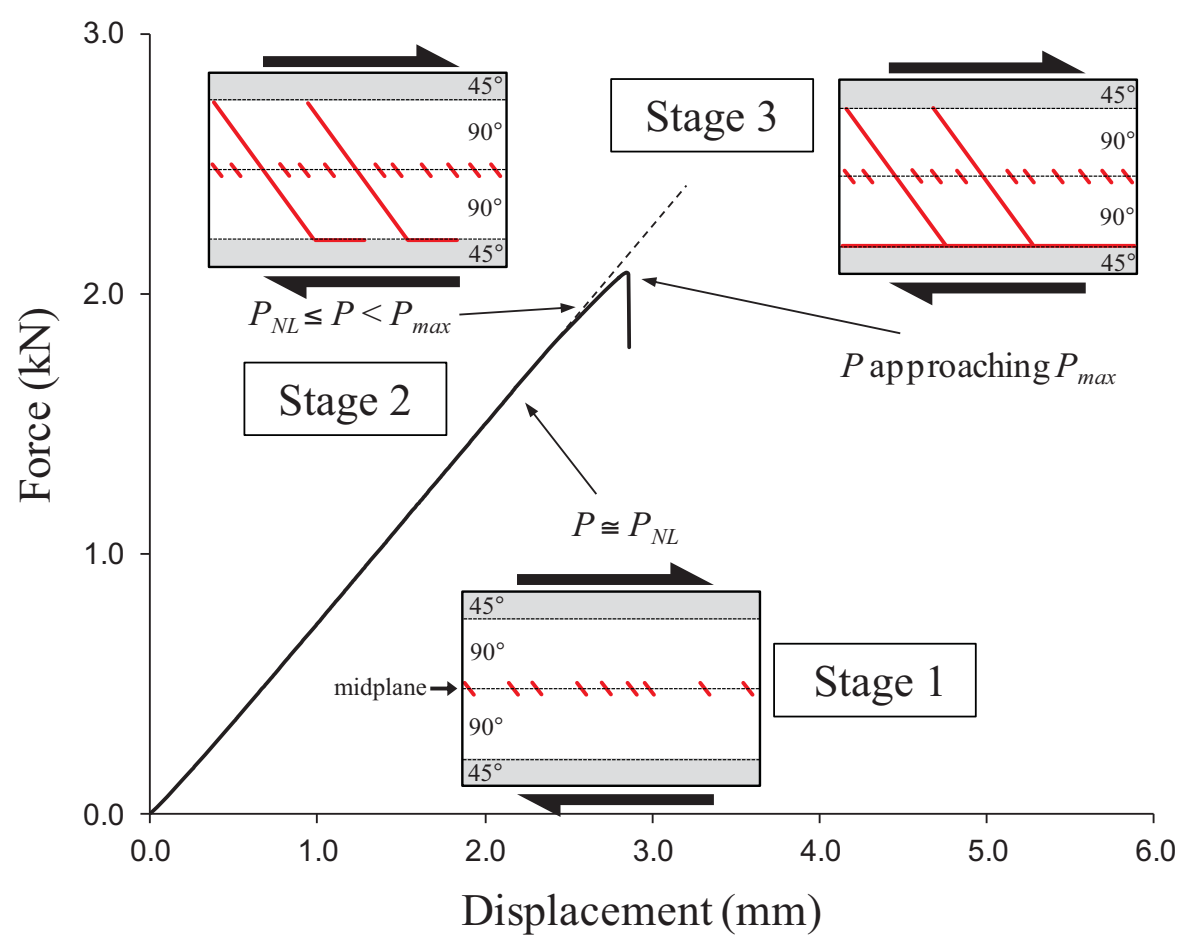

Figure 11. Stages of crack formation in the ECT specimen.

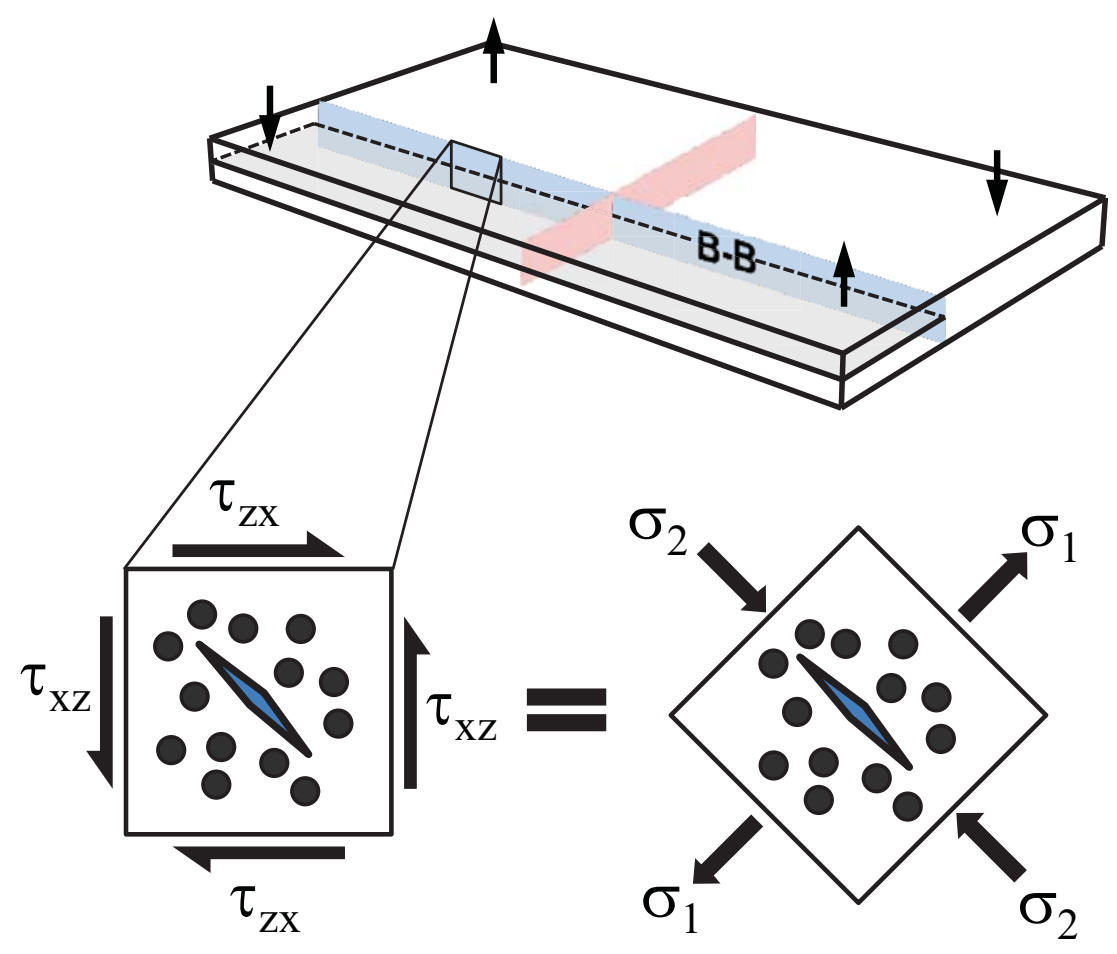

Figure 12. Principal stress resultant on plane B-B from mode III loading. 


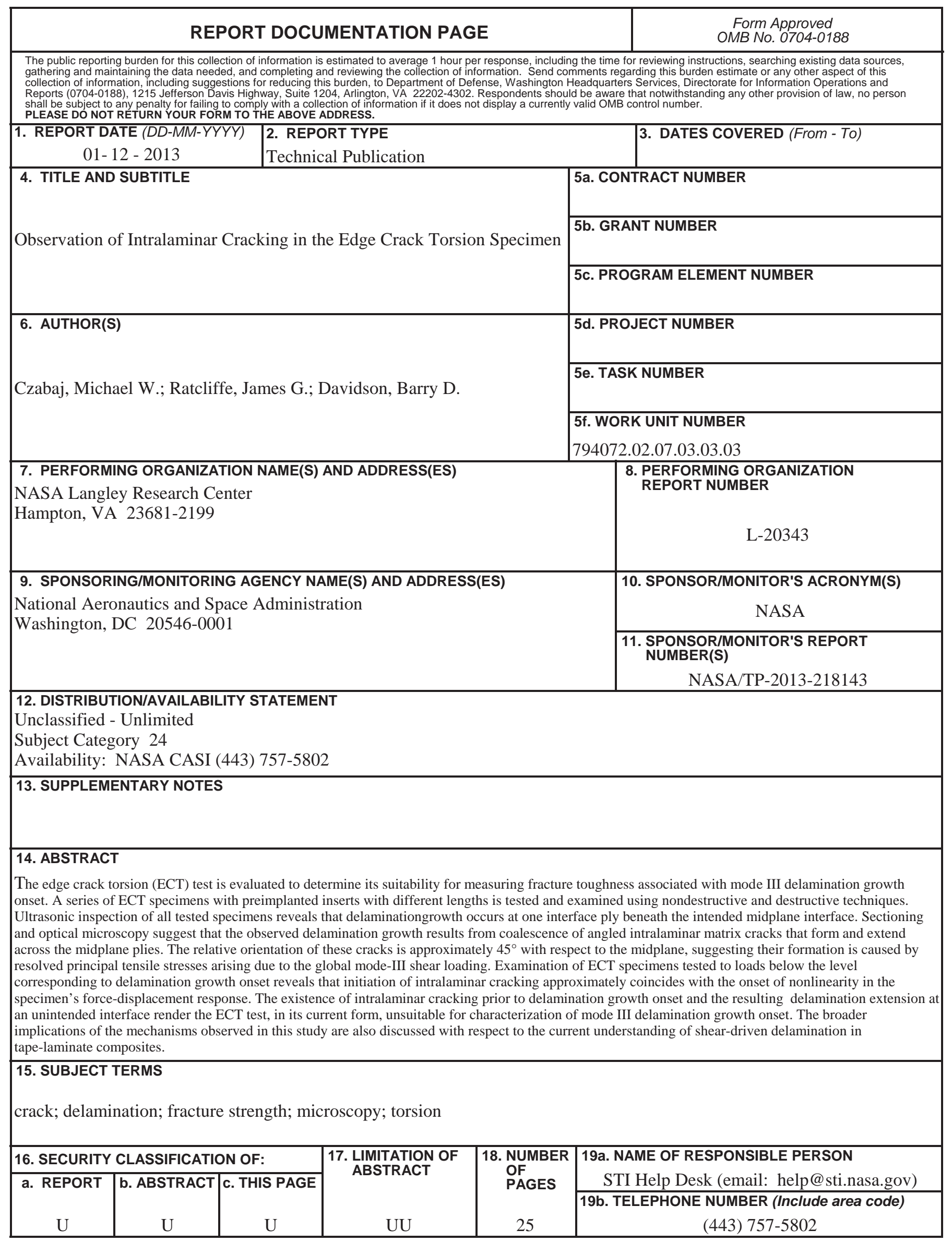

